\title{
Ambulatory blood pressure profile in hypertensive patients with $\beta$-thalassemia minor
}

\author{
Gregory Vyssoulis $^{1}$, Eva Karpanou ${ }^{2}$, Stella-Maria Kyvelou${ }^{1}$, Vanessa Tzamou ${ }^{1}$, Andreas Triantafyllou ${ }^{1}$, \\ George Theodosiadis ${ }^{3}$ and Christodoulos Stefanadis ${ }^{1}$
}

$\beta$-thalassemia trait ( $\beta$-TT) is a common genetic disorder in Mediterranean countries, including Greece. Previous studies have shown the protective effect of $\beta$-TT against myocardial infarction. However, the ambulatory blood pressure (BP) profile of such patients has not yet been investigated. Thus, the purpose of the present study was to investigate the ambulatory BP monitoring (ABPM) profile of hypertensives with $\beta$-TT, in comparison with all-cause anemic and non-anemic essential hypertensive patients. The study ultimately comprised of 8861 essential hypertensive, nondiabetic patients who were divided into three groups: group I ( $n=191$, with $\beta$-TT), group II ( $n=655$, anemic) and group III ( $n=8015$, nonanemic). All patients underwent full clinical, laboratory and echocardiographic evaluations, whereas all were subjected to ABPM. Anemia was defined as $\mathrm{Hb}<12 \mathrm{~g}$ per $100 \mathrm{ml}$ for women and $<13 \mathrm{~g}$ per $100 \mathrm{ml}$ for men, whereas patients with $\beta$-TT were self-referred. The distribution of dipping patterns among the three groups was 61.3 vs. 41.2 vs. $45.8 \%(P<0.001)$, whereas for nondippers it was 20.4 vs. 31.5 vs. $27.7 \%(P<0.001)$, for extreme-dippers it was 15.7 vs. 15.0 vs. $17.5 \%(P<0.001)$ and for reverse dippers it was 2.6 vs. 12.4 vs. 9.0\% $(P<0.001)$. Furthermore, mean daytime systolic BP (SBP) among the three groups was $140.13 \pm 7.79$ vs.

$142.02 \pm 11.61$ vs. $141.99 \pm 9.87 \mathrm{~mm} \mathrm{Hg}(P=0.03)$, and mean nighttime SBP was $125.87 \pm 10.4$ vs. $131.13 \pm 15.7$ vs. $129.62 \pm 13.31 \mathrm{~mm} \mathrm{Hg}(P<0.001)$. In the multiple regression analysis, after adjustments for age, body mass index and lipid levels, the differences among daytime and nighttime SBP remained significant at $140.18 \pm 9.84$ vs. $142.02 \pm 9.85$ vs. $141.99 \pm 9.85 \mathrm{~mm} \mathrm{Hg}(P=0.04)$ and $125.99 \pm 13.07$ vs. $131.19 \pm 13.08$ vs. $129.61 \pm 13.07 \mathrm{~mm} \mathrm{Hg}(P<0.001)$, respectively. Hypertensive patients with $\beta$-TT present with a better 24-h BP profile in comparison with anemic and nonanemic hypertensives. Thus, $\beta$-TT may function protectively in their total cardiovascular risk profile. Hypertension Research (2011) 34, 253-256; doi:10.1038/hr.2010.226; published online 2 December 2010

Keywords: ambulatory blood pressure; dipping pattern; essential hypertension; $\beta$-thalassemia trait

\section{INTRODUCTION}

It has been previously shown that assessing the circadian blood pressure (BP) profile in hypertensive patients is more effective in predicting cardiovascular risk. ${ }^{1-3}$ A nondipping pattern is associated with increased target organ damage both in hypertensives and even normotensive subjects. ${ }^{4-6}$ Specifically, left ventricular hypertrophy, microalbuminuria, carotid intima-media thickening, cerebrovascular events and renal impairment are more prominent in nondippers than in dippers. ${ }^{7-12}$

The $\beta$-thalassemia trait $(\beta-\mathrm{TT})$ is one of the most prevalent genetic diseases in Mediterranean countries. ${ }^{13}$ Several features are present in minor thalassemics, which may afford some protection against cardiovascular disease. Total cholesterol and low-density lipoprotein (LDL) levels are significantly lower in $\beta$-TT carriers when compared with controls. ${ }^{14-16}$ Furthermore, a low prevalence of arterial hypertension among both male and female minor thalassemics has been reported. ${ }^{17}$ Numerous studies have demonstrated the protective effect of minor thalassemia against myocardial infarction in male subjects. ${ }^{17-19}$ However, the reason why this effect is not seen in female subjects is enigmatic.

A nondipping BP pattern has been well established as an entity with potentially important clinical implications. Patients with $\beta$-TT present with a better cardiovascular risk profile compared with nonanemic patients. The purpose of this study was to evaluate circadian BP profiles in $\beta$-thalassemics, with essential hypertension, in comparison with all-cause anemic and nonanemic essential hypertensive patients.

\section{METHODS}

The study comprised of 10000 patients who attended our outpatient clinics for the first time from 2000 to 2010 . The study protocol was approved by the ethics committee of Hippokration Hospital. The inclusion criteria were: office systolic $\mathrm{BP}$ (SBP) values $\geqslant 140 \mathrm{~mm} \mathrm{Hg}$ and diastolic/or (DBP) $\geqslant 90 \mathrm{~mm} \mathrm{Hg}$ in three consecutive visits, 1 week apart, in our clinics, and mean ambulatory BP monitoring (ABPM) values $>125 / 80 \mathrm{~mm} \mathrm{Hg}$. Patients with acute and chronic inflammatory disease, endocrine disorders, chronic obstructive pulmonary

\footnotetext{
${ }^{1}$ Hypertension Unit, 1st Cardiology Clinic, Athens University, Hippokration, Hospital, Athens, Greece; ${ }^{2} 1$ st Cardiology Clinic Onassis Cardiosurgery Center, Athens, Greece and 3Hematology Department, Hippokration Hospital, Athens, Greece

Correspondence: Dr S-M Kyvelou, Hypertension Unit, 1st Cardiology Clinic, Athens University, Hippokration Hospital, Athens, Greece.

E-mail: kyvelou113@yahoo.gr
}

Received 14 March 2010; revised 16 August 2010; accepted 18 August 2010; published online 2 December 2010 
disease, malignancy, renal insufficiency (serum creatinine $>1.3 \mathrm{mg}$ per $100 \mathrm{ml}$ ), heart failure, recent ( $<6$ months) cerebrovascular event, coronary artery disease, ventricular arrhythmia, sinus bradycardia ( $<55$ b.p.m.), sinus tachycardia ( $>100$ b.p.m.) or atrioventricular conduction disturbances, known diabetes mellitus (previous antidiabetic treatment) and any condition preventing technically adequate ABPM were excluded from the study.

Thus, the final cohort comprised of 8861 patients, who were subjected to physical examination, medical history, anthropometric measurements, repeated clinical BP measurement, blood sampling for routine laboratory examinations and 24-h ABPM. Anemia was defined as $\mathrm{Hb}<12 \mathrm{~g}$ per $100 \mathrm{ml}$ for women and $<13 \mathrm{~g}$ per $100 \mathrm{ml}$ for men. The diagnosis of $\beta$-TT was established on the basis of the following criteria: anisocytosis, poikilocytosis, hypochromia and microcytosis (mean corpuscular $\mathrm{Hb}<27 \mathrm{pg}$, mean corpuscular volume $<80$ ), $\mathrm{Hb}$ $\mathrm{A} 2 \geqslant 3.5 \%$ or $\mathrm{Hb} \mathrm{F}$ between 2 and $10 \%$. Complete blood count was performed using a Coulter counter machine, $\mathrm{HbA} 2$ using column chromatography, $\mathrm{HbF}$ using alkaline denaturation and $\mathrm{Hb}$ electrophoresis using citrate agar. We excluded those with alpha-thalassemia or other hemoglobinopathies.

The diagnosis of hypertension was based on office BP measurements, which were taken on three consecutive visits, 1-week apart. At each visit, BP was measured, three times at $1 \mathrm{~min}$ intervals, with the patient resting comfortably, back supported in the sitting position after a 10-15-min relaxation period. A mercury sphygmomanometer was used for all measurements with a medium or a large-sized cuff, according to the patient's arm circumference.

Finally, all patients underwent ABPM for 24-h on the nondominant arm using a SpaceLabs 90207 device (SpaceLabs, Redmond, WA, USA). Technical details have been previously reported. ${ }^{20}$ The recording was analyzed to obtain 24-h daytime and nighttime average SBP, DBP and heart rate. According to the 2003 European Society of Hypertension guidelines, ${ }^{21}$ an average 24-h ABP of $124 / 79 \mathrm{~mm} \mathrm{Hg}$ was considered to be the upper limit of normality.

\section{Statistical analysis}

Statistical analysis was performed using the SPSS package for Windows, version 13.0 (SPSS, Chicago, IL, USA). Values were expressed as the means \pm s.d. or as percentages. Means were compared using an independent sample Student's $t$-test and analysis of variance when appropriate. The analysis of categorical data was carried out with the $\chi^{2}$-test. An analysis of covariance was performed to detect significant differences in dipping status between the study sub-groups after adjustment for established confounders. The limit of statistical significance was set at $P<0.05$.

\section{RESULTS}

Overall, the study population was classified in three groups: group I ( $n=191)$ with $\beta$-TT and essential hypertension, group II $(n=655)$ with all-cause anemia and without $\beta$-TT and essential hypertension and group III $(n=8015)$ nonanemic essential hypertensive patients without $\beta$-TT. $\beta$-TT patients had a lower smoking habit prevalence, had significantly lower levels of total cholesterol $(P<0.001)$, triglycerides $(P<0.001)$ and LDL $(P<0.001)$, and had significantly lower left ventricular mass index $(P<0.001)$ and higher estimated glomerular filtration rate. Baseline characteristics of the patients are presented in Table 1.

The three groups had significant differences $(P<0.001)$ in dipping pattern distribution as presented in Table 1. Overall, nondipping patterns were observed in $23 \%$ of patients with $\beta$-TT, in $43.9 \%$ of anemic patients and in $36.7 \%$ of the nonanemic patients $(P<0.0001)$. We further analyzed the day-night BP profile in the three groups, and the significant differences are presented in Table 2. The three groups did not differ in daytime SBP values $(P=\mathrm{NS})$, although $\beta$-TT patients had lower 24-h SBP values $(P=0.005)$ and lower nighttime SBP values $(P<0.0001)$. After an analysis of covariance, in which the model was adjusted for mean 24-h SBP and DBP, the dipping status distribution among the three groups was not significantly different $(P=\mathrm{NS}$ ), whereas the left ventricular mass index values after the adjustment differed slightly among the three groups $(118.1 \pm 7.8$ vs. $122.7 \pm 11.9$ vs. $120.8 \pm 8.3, P=0.02$ ).
Table 1 Baseline characteristics of the study population

\begin{tabular}{lcccr}
\hline & $\beta-T T$ & Anemics & Nonanemics & P-value \\
\hline$n$ (males) & $191(99)$ & $655(324)$ & $8015(4608)$ & $<0.001$ \\
Age (years) & $55.3 \pm 11.8$ & $56.3 \pm 15.2$ & $54.8 \pm 12.7$ & 0.022 \\
Heart rate (b.p.m.) & $75.3 \pm 7.4$ & $75.9 \pm 8.8$ & $75.0 \pm 8.1$ & 0.023 \\
Body mass index & $27.9 \pm 4.3$ & $27.7 \pm 4.4$ & $28.3 \pm 4.5$ & 0.005 \\
(kg m$\left.^{-2}\right)$ & & & & \\
Smokers (\%) & 25.9 & 34.1 & 38.7 & $<0.001$ \\
Total cholesterol & $191.7 \pm 32.4$ & $206.9 \pm 39.3$ & $220.0 \pm 40.9$ & $<0.001$
\end{tabular}

(mg per $100 \mathrm{ml}$ )

High-density lipoprotein $\quad 49.2 \pm 12.5 \quad 49.1 \pm 12.5 \quad 48.8 \pm 12.3 \quad$ NS

(mg per $100 \mathrm{ml}$ )

Triglycerides

$101.6 \pm 47.1 \quad 117.9 \pm 58.4 \quad 125.0 \pm 61.6 \quad<0.001$

(mg per $100 \mathrm{ml}$ )

Low-density lipoprotein

(mg per $100 \mathrm{ml}$ )

Peripheral systolic

$\mathrm{BP}(\mathrm{mm} \mathrm{Hg})$

Peripheral diastolic

$\mathrm{BP}(\mathrm{mm} \mathrm{Hg})$

Glucose (mg per $100 \mathrm{ml})$ eGFR $\left(\mathrm{ml} \mathrm{min}^{-1}\right.$

per $\left.1.73 \mathrm{~m}^{2}\right)$

Waist-to-hip ratio

$122.1 \pm 28.8 \quad 134.2 \pm 35.8 \quad 146.1 \pm 37.6 \quad<0.001$

$166.9 \pm 10.6 \quad 166.7 \pm 13.2 \quad 165.6 \pm 12.1 \quad 0.036$

$101.2 \pm 8.0 \quad 100.4 \pm 9.3 \quad 101.6 \pm 7.8 \quad 0.001$

Left ventricular mass

index $\left(\mathrm{g} \mathrm{m}^{-2}\right)$

Hemoglobin

(g per $100 \mathrm{ml}$ )

Hematocrit (\%)

Extreme dippers (\%)

Dippers (\%)

Nondippers (\%)

$\begin{array}{llll}92.5 \pm 11.2 & 96.4 \pm 12.2 & 96.5 \pm 12.5 & <0.001 \\ 80.5 \pm 18.7 & 73.6 \pm 23.5 & 75.6 \pm 12.0 & <0.001\end{array}$

$\begin{array}{lllll}0.86 \pm 0.08 & 0.87 \pm 0.08 & 0.88 \pm 0.08 & <0.001\end{array}$

$118.1 \pm 14.1 \quad 122.6 \pm 18.3 \quad 120.8 \pm 15.3 \quad 0.001$

$11.7 \pm 1.33 \quad 11.7 \pm 0.81 \quad 14.4 \pm 1.2<0.001$

$\begin{array}{llll}37.2 \pm 3.9 & 37.0 \pm 2.3 & 43.7 \pm 3.4 & <0.001\end{array}$

$\begin{array}{llll}15.7 & 15.0 & 17.5 & <0.001\end{array}$

$\begin{array}{llll}61.3 & 41.2 & 45.8 & <0.001\end{array}$

$\begin{array}{llll}20.4 & 31.5 & 27.7 & <0.001\end{array}$

$\begin{array}{lllll}\text { Reverse dippers (\%) } & 2.6 & 12.4 & 9.0 & <0.001\end{array}$

Abbreviations: $\beta$-TT, $\beta$-thalassemia trait; b.p.m., beats per minute; BP, blood pressure; eGFR, estimated glomerular filtration rate.

Table 2 Daytime and nighttime BP levels in the three study subgroups

\begin{tabular}{lcccr}
\hline & $\begin{array}{c}\beta-T T \\
(\mathrm{n}=191)\end{array}$ & $\begin{array}{c}\text { Anemics } \\
(\mathrm{n}=655)\end{array}$ & $\begin{array}{c}\text { Nonanemics } \\
(\mathrm{n}=8015)\end{array}$ & P-value \\
\hline Daytime SBP (mm Hg) & $140.1 \pm 7.7$ & $142.0 \pm 11.6$ & $141.9 \pm 9.8$ & 0.038 \\
Nighttime SBP (mm Hg) & $125.8 \pm 10.4$ & $131.1 \pm 15.7$ & $129.6 \pm 13.3$ & $<0.001$ \\
24-h SBP (mm Hg) & $137.0 \pm 7.9$ & $139.7 \pm 12.0$ & $139.2 \pm 10.0$ & 0.005 \\
Daytime DBP (mm Hg) & $87.5 \pm 6.7$ & $87.0 \pm 8.4$ & $88.2 \pm 7.8$ & 0.007 \\
Nighttime DBP (mm Hg) & $75.0 \pm 7.3$ & $76.5 \pm 9.4$ & $76.9 \pm 8.7$ & 0.003 \\
24-h DBP (mm Hg) & $84.6 \pm 6.5$ & $84.7 \pm 8.2$ & $85.7 \pm 7.6$ & $<0.001$
\end{tabular}

Abbreviations: $\beta$-TT, $\beta$-thalassemia trait; BP, blood pressure; DBP, diastolic blood pressure; $\mathrm{SBP}$, systolic blood pressure.

In multivariate analysis, daytime, nighttime and 24-h SBP and DBP were set as the dependent variables and the model was adjusted for age, body mass index, lipid profile, smoking, estimated glomerular filtration rate and glucose level. The differences among the three study sub-groups remained significant (Table 3 ).

\section{DISCUSSION}

The main findings of the present study are as follows: (1) essential hypertensive patients with $\beta$-TT present with a better dipping profile 
Table 3 Analysis of covariance in the three study groups after adjustment for several covariates

\begin{tabular}{lcccr}
\hline & $\begin{array}{c}\beta-T T \\
(\mathrm{n}=191)\end{array}$ & $\begin{array}{c}\text { Anemics } \\
(\mathrm{n}=655)\end{array}$ & $\begin{array}{c}\text { Nonanemics } \\
(\mathrm{n}=8015)\end{array}$ & P-value \\
\hline Daytime SBP (mm Hg) & $140.1 \pm 9.8$ & $142.0 \pm 9.8$ & $141.9 \pm 9.8$ & 0.041 \\
Nighttime SBP (mm Hg) & $125.9 \pm 13.0$ & $131.1 \pm 13.0$ & $129.6 \pm 13.0$ & $<0.001$ \\
24-h SBP (mm Hg) & $137.1 \pm 9.9$ & $139.7 \pm 9.9$ & $139.2 \pm 9.9$ & 0.006 \\
Daytime DBP (mm Hg) & $87.6 \pm 7.2$ & $87.3 \pm 7.2$ & $88.1 \pm 7.2$ & 0.011 \\
Nighttime DBP (mm Hg) & $75.0 \pm 8.5$ & $76.1 \pm 8.5$ & $76.9 \pm 8.5$ & 0.012 \\
24-h DBP (mm Hg) & $84.9 \pm 7.0$ & $85.0 \pm 7.0$ & $85.0 \pm 7.0$ & 0.034 \\
\hline
\end{tabular}

Abbreviations: $\beta$-TT, $\beta$-thalassemia trait; DBP, diastolic blood pressure; SBP, systolic blood pressure.

than all-cause anemic and nonanemic essential hypertensives, (2) this favorable dipping status is independent of several confounders and (3) essential hypertensive patients with $\beta$-TT have a better lipid profile and left ventricular mass index than the other two study sub-groups. To our knowledge, this is the first study demonstrating such findings in a large cohort of essential hypertensive patients.

The present study results, considering the lipid profile of patients with $\beta$-TT, are in line with previous reports. ${ }^{14-16}$ It has been suggested that accelerated erythropoiesis and increased uptake of LDL by macrophages and histiocytes in the reticuloendothelial system are the main determinants of low-plasma cholesterol levels in these individuals. $^{22,23}$ Furthermore, hemolysis and iron loading may also affect LDL oxidation ${ }^{24,25}$ and, thus, LDL levels in these patients, leading to a better cardiovascular risk profile.

It has been previously reported that patients with $\beta$-TT are at lower risk for arterial hypertension. ${ }^{17,26}$ However, in the present study, all patients were essential hypertensives. Still, our results document a protective dipping pattern in these subjects in comparison with allcause anemic and nonanemic hypertensives. Specifically, patients with $\beta$-TT were mostly dippers, whereas 24 -h SBP and DBP were independently and significantly lower than in the other two study sub-groups. It is well known that polycythemia and high hematocrit levels are considered to be cardiovascular risk factors and are also associated with elevated $\mathrm{BP}^{27}$ In the present study, our data suggest that nonanemic hypertensives had higher 24-h SBP and DBP values and presented with altered dipping profiles.

Furthermore, the fact that 24-h mean BP, DBP and daytime BP were lower in patients with $\beta$-TT may be attributable to specific hemodynamic adjustments seen initially in anemia, including systematic arterial dilatation, which leads to decreased systemic vascular resistance, reduced afterload, and thus improved stroke volume. ${ }^{28,29}$ Moreover, anemia decreases blood viscosity, which may improve venous return and augment preload. ${ }^{30,31,32}$ A normal dipping pattern is mainly due to a decrease in cardiac output, whereas nighttime systemic vascular resistance remains similar to daytime vascular resistance or may even be increased. The fact that anemic hypertensive patients in the present study did not present with as favorable a dipping profile as $\beta$-TT patients, raises the hypothesis that more complex mechanisms may be involved. The onset of anemia and its chronic effects, along with iron accumulation and ferritin levels, which are known risk factors, may account for the differences seen. However, because these data are not available for these patients, this remains a hypothesis. Moreover, in the present study, left ventricular mass index was not significantly different between all cause anemic and nonanemic hypertensive patients, which points to possible unknown mechanisms responsible for the less affected left ventricular mass observed in patients with $\beta$-TT.
The present study has some limitations. First, the number of patients included in the $\beta$-TT subgroup is relatively small. However, because the findings have been compared with all-cause anemia hypertensive patients and nonanemic hypertensive patients, these results can be considered valid and strong. Second, the study population underwent only one ABPM measurement, which may raise discussion about the reproducibility of the results. However, because it is a large cohort, we believe that one measurement is adequate to draw our conclusions.

In conclusion, in the present study, hypertensive patients with $\beta$-TT present with a significantly and independently better dipping status profile in comparison with all-cause anemic and non-anemic essential hypertensive patients. Furthermore, these patients have lower lipidindex levels and superior left ventricular function in comparison with the other two study sub-groups.

\section{CONFLICT OF INTEREST}

The authors declare no conflict of interest.

1 Verdecchia P, Porcellati C, Schillaci G, Borgioni C, Ciucci A, Battistelli M, Guerrieri M, Gatteschi C, Zampi I, Santucci A, Reboldi G. Ambulatory blood pressure. An independent predictor of prognosis in essential hypertension. Hypertension 1994; 24: 793801

2 Dolan E, Stanton A, Thijs L, Hinedi K, Atkins N, McClory S, Den Hond E, McCormack P, Staessen JA, O'Brien E. Superiority of ambulatory over clinic blood pressure measurement in predicting mortality: the Dublin outcome study. Hypertension 2005; 46: 156-161.

3 Clement DL, De Buyzere ML, De Bacquer DA, de Leeuw PW, Duprez DA, Fagard RH Gheeraert PJ, Missault LH, Braun JJ, Six RO, Van Der Niepen P, O'Brien E. Prognostic value of ambulatory blood-pressure recordings in patients with treated hypertension. N Engl J Med 2003; 348: 2407-2415.

4 Mancia G, Parati G. The role of blood pressure variability in end-organ damage. J Hypertens Supp/ 2003; 21: 17-23.

5 White WB. Relevance of blood pressure variation in the circadian onset of cardiovascular events. J Hypertens Supp/ 2003; 21: 9-15.

6 Pickering T. Future developments in ambulatory blood pressure monitoring and selfblood pressure monitoring in clinical practice. Blood Press Monit 2002; 7: 21-25.

7 Cuspidi C, Macca G, Sampieri L, Fusi V, Severgnini B, Michev I, Salerno M, Magrini F, Zanchetti A. Target organ damage and non-dipping pattern defined by two sessions of ambulatory blood pressure monitoring in recently diagnosed essential hypertensive patients. J Hypertens 2001; 19: 1539-1545.

8 Verdecchia P, Schillaci G, Guerrieri M, Gatteschi C, Benemio G, Boldrini F, Porcellati C. Circadian blood pressure changes and left ventricular hypertrophy in essential hypertension. Circulation 1990; 81: 528-536.

9 Shimada K, Kawamoto A, Matsubayashi K, Ozawa T. Silent cerebrovascular disease in the elderly. Correlation with ambulatory pressure. Hypertension 1990; 16: 692-699.

10 Covic A, Haydar AA, Goldsmith DJ. Recent insights from studies using ambulatory blood pressure monitoring in patients with renal disease. Curr Opin Nephrol Hypertens 2003; 12: 645-648.

11 Rahman M, Griffin V, Heyka R, Hoit B. Diurnal variation of blood pressure; reproducibility and association with left ventricular hypertrophy in hemodialysis patients. Blood Press Monit 2005; 10: 25-32.

12 Goto N, Uchida K, Morozumi K, Ueki T, Matsuoka S, Katayama A, Haba T, Tominaga Y, Fukuda M, Nakao A, Kimura G. Circadian blood pressure rhythm is disturbed by nephrectomy. Hypertens Res 2005; 28: 301-306.

13 Karimi M, Ghavanini A, Kadivar MR. Regional mapping of the gene frequency of $\beta$-thalassemia in Fars province, Iran during 1997-1998. Iran J Med Sci 200; 25 : 134-137.

14 Maioli M, Pettinato S, Cherchi GM, Giraudi D, Pacifico A, Pupita G, Tidore MG. Plasma lipids in b-thalassemia minor. Atherosclerosis 1989; 75: 245-248.

15 Fessas P, Stamatoyannopoulous G, Keys A. Serum cholesterol and thalassemia trait. Lancet 1963; 1: 1182-1183.

16 Botliger LE, Carlson LA. Relation between serum cholesterol and triglyceride concentration and hemoglobin values in non-anemic healthy persons. BMJ 1972; 3: 731-733.

17 Gallerani M, Scapldi C, Cicognani I, Ricci A, Martinelli L, Cappato R, Manfredini R, Dall'Ara G, Faggioli M, Pareschi PL. Thalassemia trait and myocardial infarction: low infarction incidence in male subjects confirmed. J Inter Med 1991; 230: 109-111.

18 Crowley JP, Sheth S, Capone RJ, Schilling RF. A paucity of thalassemia trait in Italian men with myocardial infarction. Acta Haematol 1987; 78: 249-251.

19 Wang $\mathrm{CH}$, Schilling RF. Myocardial infarction and thalassemia trait: an example of heterozygote advantage. Am J Hematol 1995; 49: 73-75. 
20 Cuspidi C, Meani S, Fusi V, Severgnini B, Valerio C, Catini E, Leonetti G, Magrini F, Zanchetti A. Metabolic syndrome and target organ damage in untreated essential hypertensives. J Hypertens 2004; 22: 1991-1998.

21 Mancia G, Laurent S, Agabiti-Rosei E, Ambrosioni E, Burnier M, Caulfield MJ, Cifkova R, Clément D, Coca A, Dominiczak A, Erdine S, Fagard R, Farsang C, Grassi G, Haller $\mathrm{H}$, Heagerty A, Kjeldsen SE, Kiowski W, Mallion JM, Manolis A, Narkiewicz K, Nilsson $\mathrm{P}$, Olsen MH, Rahn KH, Redon J, Rodicio J, Ruilope L, Schmieder RE, Struijker-Boudier HA, Van Zwieten PA, Viigimaa M, Zanchetti A. Reappraisal of European guidelines on hypertension management: a European Society of Hypertension Task Force document. Blood Press 2009; 18: 308-347.

22 Scott MD, Van den Berg JJM, Repka T, Rouyer-Fessard Ph, Hebbel RP, Beuzard Y, Lubin B. Effect of excess a-hemoglobin chains on cellular and membrane oxidation in model b-thalassemic erythrocytes. J Clin Invest 1993; 91: 1706-1712.

23 Esterbauer H, Gebicki J, Puhl H, Jurgens G. The role of lipid peroxidation and antioxidants in oxidative modification of LDL. Free Radic Biol Med 1992; 13: 341-390.

24 Gillum RF. Body iron stores and atherosclerosis. Circulation 1997; 96: 3261-3263.

25 Altamentova SM, Marva E, Shaklai N. Oxidative interaction of unpaired hemoglobin chains with lipids and proteins: a key for modified serum lipoproteins in thalassemia. Arch Biochem Biophys 1997; 345: 39-46.
26 Karimi M, Marvasti VE, Motazedian S, Sharifian M. Is $\beta$-thalassemia trait a protective factor against hypertension in young adults? Ann hematol 2006; 85: 29-31.

27 Namazi M. Minor thalassemia as a protective factor against cerebrovascular accidents. Med Hypotheses 2002; 59: 361-362.

28 Cavelaars M, Tulen JH, van Bemmel JH, Mulder PG, van den Meiracker AH. Reproducibility of intra-arterial ambulatory blood pressure: effects of physical activity and posture. J Hypertens 2004; 22: 1105-1112.

29 O'Shea JC, Murphy MB. Nocturnal blood pressure dipping: a consequence of diurnal physical activity blipping? Am J Hypertens 2000; 13: 601-606.

30 Duke M, Abelmann WH. The hemodynamic response to chronic anemia. Circulation 1969; 39: 503-515.

31 Anand IS, Chandrashekhar Y, Ferrari R, Poole-Wilson PA, Harris PC. Pathogenesis of oedema in chronic severe anemia: studies of body water and sodium, renal function, haemodynamic variables, and plasma hormones. Br Heart J 1993; 70: 357-362.

32 Vyssoulis G, Karpanou E, Kyvelou S-M, Tzamou V, Theodosiadis G, Stefanadis C. Ambulatory blood pressure profile in anemic hypertensive patients. Int J Cardiol 2009; 6 [e-pub ahead of print]. 